\title{
Programa Cultura Viva e o campo organizacional da cultura: análise de políticas públicas pela perspectiva institucionalista
}

\author{
Anny Karine de Medeiros \\ Fundação Getulio Vargas / Escola de Administração de Empresas de São Paulo \\ São Paulo / SP - Brasil \\ Mário Aquino Alves \\ Fundação Getulio Vargas / Escola de Administração de Empresas de São Paulo \\ São Paulo / SP - Brasil \\ Marta Ferreira Santos Farah \\ Fundação Getulio Vargas / Escola de Administração de Empresas de São Paulo \\ São Paulo / SP - Brasil
}

\begin{abstract}
O presente artigo tem como objetivo analisar transformações ocorridas no campo organizacional da cultura no estado de São Paulo a partir da implementação do programa federal Arte Cultura e Cidadania - Cultura Viva. Com base em uma abordagem exploratória de caráter descritivo e tendo por referência a perspectiva institucionalista das organizações, o artigo mostra como o Programa Cultura Viva, ao incluir novas organizações no campo organizacional da cultura, modifica essas organizações, tornando-as semelhantes às já integrantes, e, ao mesmo tempo, provoca uma mudança simbólica, dado que as organizações inseridas muito diferem daquelas que são historicamente reconhecidas e legitimadas.
\end{abstract}

Palavras-chave: política cultural; campo organizacional; Cultura Viva; análise institucional.

Programa Cultura Viva y el campo organizacional de la cultura: análisis de las políticas públicas por parte de la perspectiva institucional

Este artículo tiene como objetivo analizar los cambios en el campo organizacional de la cultura en São Paulo, a partir de la implementación del programa federal Arte Cultura y Ciudadanía — Cultura Viva. Basado en un enfoque exploratorio y descriptivo, utilizando como referencia la perspectiva institucionalista de las organizaciones, el artículo muestra como el Programa Cultura Viva, para incluir

DOI: http://dx.doi.org/10.1590/0034-7612130337

(c) (i)

Artigo recebido em 9 set. 2014 e aceito em 29 abr. 2015.

Versão preliminar deste artigo foi apresentada no XXXVII Encontro da Associação Nacional de Pós-Graduação e Pesquisa em Administração, realizado em 2013 no Rio de Janeiro, sob título "Programa Cultura Viva como política pública: análise de políticas públicas pela perspectiva institucional das organizações". 
nuevas organizaciones en el campo organizacional, modifica estas organizaciones, haciéndolas similares aquellas ya incluidas, y al mismo tiempo provoca un cambio simbólico cambio en el campo, ya que las organizaciones insertadas son muy diferentes de aquellas históricamente reconocidas como parte del campo organizacional de la cultura.

Palabras clave: políticas culturales; campo organizacional; Cultura Viva; análisis institucionalista.

Cultura Viva Program and the organizational field of culture: public policies analysis from an institutional perspective

This article aims to analyze the transformations occurred in the organizational field of culture in the State of São Paulo for the sake of the implementation of the National Program for Culture, Art and Citizenship - "Cultura Viva". Based on an exploratory approach of descriptive character and having as reference to the institutional perspective of organizations, the article shows how the program, by including new organizations into the organizational field of culture, modifies these organizations, making them similar to those already included. At the same time, the program causes a symbolic change in this field, as the insertion of organizations differ greatly from those that are historically known and recognized as part of the organizational field of culture.

KEYwords: cultural policy; organizational field; Cultura Viva; institutional analysis.

\section{Introdução}

O presente artigo tem como objetivo analisar as transformações ocorridas no campo organizacional da cultura no estado de São Paulo a partir da implementação do programa Arte Cultura e Cidadania (Cultura Viva), verificando se a inclusão de novas organizações culturais e novas regras mudou o padrão existente no campo organizacional da cultura, ou se essas organizações apenas se adequaram a esse campo. Propõe-se assim uma interlocução entre a literatura de teoria institucionalista em organizações e estudos de políticas públicas, dado que a teoria institucionalista permite entender aspectos do papel indutor das políticas públicas em campos organizacionais, aspectos estes ainda não plenamente abordados pelos estudos de políticas públicas.

Importante alteração no campo da cultura ocorreu no Brasil, desde os anos 1990, quando a política cultural passou a ser marcada por um modelo no qual a execução de ações culturais é realizada por organizações privadas (lucrativas ou não) e financiada por recursos de seus tributos devidos, modelo conhecido por mecenato. A renúncia fiscal, regulamentada pela Lei Rouanet (Lei no 8.313/1991), passa então a ser a principal política cultural do período. Se, por um lado, esse modelo ampliou o volume de recursos no campo, por outro lado, gerou concentração regional de projetos e restrição de recursos e ações culturais: poucas organizações tinham acesso a tais recursos (Olivieri, 2004; Silva e Araujo, 2010). A seleção de quais organizações que seriam - ou não — beneficiadas pelos incentivos fiscais moldou o campo das organizações culturais. Como mostram trabalhos sobre o período (Reis, 2003; Olivieri, 2004; Medeiros, 2013), embora um perfil diversificado de organizações e de ativi- 
dades culturais busque financiamento por meio do modelo do mecenato, critérios explícitos e implícitos levaram à concentração de investimento em determinados tipos de ações culturais e determinado tipo de organização cultural, em especial aquelas com estrutura própria de captação de recursos.

Buscando reverter a concentração regional e o direcionamento de recursos, o programa Cultura Viva foi proposto pelo Ministério da Cultura (MinC) em 2004 com o intuito de incentivar organizações culturais excluídas dos circuitos de financiamento moldados pelo mecenato, mas que realizavam ações culturais. Essas organizações culturais se candidatam a editais do programa, por meio de um plano de trabalho por elas desenvolvido, contendo as ações que serão realizadas com os recursos do convênio. As organizações selecionadas tornam-se então pontos de cultura, passando a integrar uma rede de ações, ou rede de pontos de cultura (MinC, 2013). É central, portanto, na concepção do programa, a ideia de rede (de ações culturais), integrada por "pontos" que se comunicam e articulam (os pontos de cultura). Ao incentivar ações realizadas nas comunidades, o programa intentou valorizar ações e organizações no campo organizacional da cultura, seja por meio do seu reconhecimento por uma política pública, seja por permitir acesso a uma nova fonte de recursos.

O presente artigo procura analisar esse programa na perspectiva de mudanças no campo organizacional, tendo por referência a teoria institucionalista de estudos organizacionais, para verificar, de um lado, como organizações de determinada comunidade, apoiadas pelo Programa Cultura Viva, são transformadas pelo apoio governamental e, de outro, se sua entrada no campo organizacional provoca alterações nesse campo.

Para o presente artigo, entende-se que um campo organizacional é aquele formado por organizações que constituem uma reconhecida área de produção de bens ou serviços, sejam essas organizações fornecedoras, produtoras ou agências (Powell e Dimaggio, 1983:148-149). O campo organizacional, assim como outros campos no mundo social, assume a dimensão da disputa como elemento constitutivo (Bourdieu, 1996). Assim, as ações relevantes ocorrem entre os atores desse referido campo (Fligstein e McAdam, 2012), que partilham um mesmo sistema de significados, interagindo de forma mais frequente entre si do que com organizações (atores) fora deste campo (Reay e Hinings, 2005).

Como demonstra a teoria, há mudança no campo organizacional quando (1) novos atores entram no campo organizacional, e (2) novas práticas são incorporadas a um campo existente, modificando o próprio campo (Rao, Morrill e Zald, 2000; Emirbayer e Mische, 1998; Seo e Creed, 2002; Moody, 2008). Há então um movimento bidirecional com a inclusão de novas organizações: estas sofrem pressões e são modificadas, ao mesmo tempo que modificam o campo no qual estão inseridas, por estabelecerem novas práticas (Medeiros, 2013). O presente artigo busca demonstrar como mudanças em campos organizacionais podem ser provocadas por políticas públicas, utilizando-se de uma aproximação possível, mas ainda pouco explorada pela literatura brasileira, entre esses dois campos de estudos. Os estudos organizacionais permitem identificar como uma política cultural pode impactar, em grau restrito, um campo organizacional (Rao, Morrill e Zald, 2000), e potencialmente, em sentido mais amplo, a sociedade que o envolve, por incentivar e, consequentemente, induzir um determinado 
tipo de ação cultural (Bourdieu, 1996). Partindo dessa perspectiva, o presente artigo busca verificar se as organizações culturais beneficiadas pelo programa Cultura Viva se modificam ao serem selecionadas pelo programa e, em caso afirmativo, que modificações foram essas. Por fim, sugere-se que a entrada dessas organizações no campo organizacional da cultura o modifica, dado que as organizações inseridas muito diferem daquelas que são reconhecidas historicamente como parte do campo organizacional da cultura, marcando uma mudança simbólica no modo de entender o papel das políticas culturais.

\section{Metodologia e desenho da pesquisa}

O presente artigo se baseia em uma abordagem exploratória de caráter descritivo, com levantamento de dados primários e secundários, aliado a uma pesquisa quantitativa (survey). A revisão de literatura adota a perspectiva institucionalista organizacional para compreender uma política pública como um sistema de políticas interorganizacionais (Milward, 1982). Assim, a unidade de análise deste estudo não é uma organização em particular, nem tão pouco a política de cultura, mas o sistema interorganizacional que ela forma, que caracteriza o próprio campo organizacional da cultura (Powell e DiMaggio, 1983; Reay e Hinings, 2005).

Com base nesse referencial analítico, procurou-se verificar como o processo de alteração de uma política pública, por meio da implementação do Programa Cultura Viva, afetou as organizações pertencentes ao campo organizacional da cultura e as ações organizacionais, a partir da definição de novas regras institucionais que abriram espaço para que novas organizações e ações culturais se estabelecessem e, consequentemente, modificando esse campo organizacional já institucionalizado (Fligstein e McAdam, 2012). Análises de cunho institucionalista sobre políticas públicas "constituem um lugar analítico e metodológico (...) com uma postura teórica muito aberta, onde a hierarquia dos fatores mais importantes para o estudo de cada caso é dada a posteriori segundo as conjunturas encontradas" (Marques, 1997:03).

Neste sentido, o modelo interpretativo desta pesquisa parte de uma observação longitudinal dos efeitos da implementação do Programa Cultura Viva, procurando entender mudanças em formas organizacionais, a emergência de novos formatos organizacionais, a articulação de ideias e crenças privadas (ou tornadas públicas), novas práticas e padrões que permitissem interpretar a natureza das ligações entre macro e microestruturas e a inter-relação entre ações e instituições (Barley e Tolbert, 1997).

Os dados primários da pesquisa vieram de duas frentes. A fim de detalhar o perfil das organizações que se tornam pontos de cultura por meio dos editais (permitindo que se inferisse a entrada de novas organizações no campo), bem como sua experiência com o programa Cultura Viva, foi elaborada uma pesquisa no formato survey: um questionário estruturado com 20 perguntas abertas e fechadas foi enviado para pontos e pontões de cultura do estado de São Paulo. Esse recorte foi escolhido, pois o estado de São Paulo reúne a maior quantidade de organizações culturais vinculadas às ações realizadas pelo programa Cultura Viva, se destaca na quantidade de organizações culturais existentes e no volume recursos transferidos 
pelo modelo de mecenato (Medeiros, 2013). Essa escolha é reforçada pelo número de fundações privadas e associações sem fins lucrativos existentes, aproximadamente 59,6 mil, ou seja, $20 \%$ do total nacional (IBGE, 2010).

O questionário foi disponibilizado em um site da internet e divulgado para listas de e-mails e grupos do universo escolhido, recebendo 31 respostas voluntárias de gestores de pontos de cultura. Os dados coletados pelo survey foram utilizados tanto na descrição do programa Cultura Viva, quanto no detalhamento dos pontos e pontões de cultura do estado de São Paulo, além de suscitar novos questionamentos sobre o programa Cultura Viva. Tais questionamentos foram detalhados por meio de entrevistas semiestruturadas com o idealizador do programa e secretário responsável pela sua implementação, e com a coordenadora da rede paulista de pontos de cultura (Medeiros, 2013). Foram entrevistados, ainda, cinco gestores de pontos de cultura, e buscou-se garantir que as entrevistas trouxessem visões de organizações de diferentes perfis, que permitissem, portanto, desvelar novas ideias, crenças e padrões que poderiam estar se institucionalizando.

Os dados secundários levantados são referentes a financiamento, projetos selecionados e financiados pelas políticas culturais, e convênios firmados com o poder público. Os dados são provenientes da base de dados do Ministério da Cultura (MinC), do Sistema de Apoio às Leis de Incentivo à Cultura (SalicNet), e do Sistema de Gestão de Convênios e Contratos de Repasse do Governo Federal (Siconv).

Com os dados secundários, respostas ao questionário e entrevistas, buscou-se reunir elementos suficientes para entender como, de um lado, as organizações, ao se tornarem pontos de cultura, são transformadas pelo apoio governamental e, de outro, se sua entrada no campo organizacional provoca alterações nesse campo, utilizando para tanto a perspectiva de mudanças no campo organizacional.

\section{Análise institucionalista de políticas públicas: uma visão organizacional}

Na ciência política, pode-se afirmar a existência de três perspectivas neoinstitucionalistas: a racionalista, a sociológica e a histórica (Hall e Taylor, 2003). Para a perspectiva racionalista, instituições são criações intencionais e deliberadas - a partir de um processo contratual de consentimento voluntário entre os diversos atores políticos - no sentido de aumentar a eficiência do funcionamento da sociedade. De acordo com a perspectiva sociológica, a criação, permanência ou mudança de instituições não é o resultado de um processo funcional de busca de maior eficiência, mas sim de uma busca por maior legitimidade. Para a perspectiva histórica, instituições são estabelecidas a partir de um processo de diferentes disputas e acordos entre grupos organizados, possuindo um efeito contínuo sobre o processo decisório subsequente e sobre a própria criação de instituições; assim, a "dependência de trajetória" (path dependence) associada às diferentes relações de poder incrustradas nas instituições existentes é um importante fator explicativo para a persistência de instituições e políticas ao longo do tempo. 
As perspectivas institucionais predominantes na ciência política são a racional e a histórica (Marques, 1997), sendo esta última predominante para o entendimento da evolução das políticas públicas ao longo do tempo. Não por outro motivo, alinham-se a essa perspectiva os trabalhos que explicam o papel da "dependência da trajetória", isto é, a forma como decisões políticas se sucedem no tempo, uma vez que as decisões passadas restringiriam as opções futuras dos criadores de políticas (Pierson, 2000), permitiriam evoluções incrementais (Thelen, 1999), que resultariam de mecanismos de reprodução que "aprisionariam" (lock-in) um determinado padrão institucional, impedindo sua modificação.

A "dependência de trajetória" é questionada por alguns autores, menos por afirmar a persistência de instituições ao longo do tempo, mas pela maneira como lida com o papel da percepção e da interpretação dos atores de uma instituição, até mesmo no que diz respeito à reprodução da "trajetória" (Peter, Pierre e King, 2005). Por esse motivo, é interessante complementar uma análise de permanência da instituição, combinando-a pela consideração da capacidade de agência de atores individuais e coletivos, como faz a perspectiva sociológica.

Nascida no interior da teoria das organizações, a perspectiva sociológica - ou teoria institucional das organizações - enfatiza a natureza altamente interativa das relações entre as instituições e a ação individual, na qual cada polo constitui o outro. "Quando agem conforme uma convenção social, os indivíduos se constituem simultaneamente como atores sociais, empreendem ações dotadas de significado social e reforçam a convenção a que obedecem (...) a ação está estreitamente ligada à interpretação" (Hall e Taylor, 2003:210).

\subsection{Os campos organizacionais e os padrões isomórficos}

O cotidiano das pessoas é marcado por intensos e inúmeros contatos com diferentes tipos de organizações, como escolas, hospitais, clubes, universidades, restaurantes, supermercados, órgãos públicos, lojas, entre outros tipos. Por serem sistemas sociais complexos, as organizações sofrem influência e influenciam outras organizações a todo momento, sendo importante analisar como as organizações operam, como se adaptam e como influenciam o contexto e o ambiente em que atuam, questões que vêm sendo tratadas pelos estudos organizacionais desde a década de 1960 (Barley, 2010:778).

No que diz respeito às relações entre estado e sociedade, Bartley (2007) analisa as estratégias que organizações utilizam para influenciar o governo - e outras organizações — configurando o ambiente no qual atuam. As organizações constituintes de um campo (Powell e Dimaggio, 1983), especialmente organizações financiadoras, influenciam o apoio governamental e selecionam quais organizações irão apoiar diretamente. Com isso "moldam" o campo ao favorecer a inclusão de organizações mais "moderadas" e "profissionais", permitindo que estas se multipliquem, em detrimento de outras, com visões e opiniões divergentes do padrão do campo organizacional ou menos profissionalizadas. Com isso, aquelas organizações que não estão alinhadas aos interesses do mainstream acabam por receber menos recursos, che- 
gando a ser excluídas de um campo organizacional. Nesse sentido, a ação das organizações financiadoras canaliza organizações para compor (ou reconstruir) campos organizacionais.

Campo organizacional é aquele formado por organizações que, ao estarem agregadas, constituem uma reconhecida área, sejam estas organizações fornecedoras, produtoras, agências reguladoras ou outras organizações voltadas para um mesmo objetivo (Powell e Dimaggio, 1983). Assim, parte-se da premissa de que "a ação coletiva ocorre no interior e ao largo de campos" (Fligstein e McAdam, 2012, posição 4392-4403).

Interessante notar que a teoria institucionalista afirma ser mais fácil identificar quem não faz parte de um campo organizacional do que identificar quem o faz (Powell e DiMaggio, 1983). Entre os inúmeros campos organizacionais existentes, Reis (2003) descreve o campo das organizações culturais que envolve: os criadores culturais, os agentes intermediários culturais, as instituições culturais, a iniciativa privada e o próprio Estado. Por exemplo, uma organização voltada para produção fonográfica tem um produto diferente do serviço realizado por uma organização produtora de espetáculos, mas ambas as organizações podem se relacionar, e compõem um mesmo campo organizacional.

Ainda sobre a composição de campos organizacionais, uma vertente da teoria institucionalista aponta como algumas organizações têm maior densidade que outras, dentro de um mesmo campo, o que as faz influenciar tanto as demais organizações quanto o campo organizacional em si (Ruef, 2000; Alves e Koga, 2006).

Densidade, nesse sentido, atua para homogeneização do campo, direcionando e engessando as organizações segundo o mesmo padrão, ou forma, daquelas organizações com maior poder, ou densidade. Em geral, estas pressões que procuram criar homogeneidade em um campo, tornando as organizações mais similares, são o que Powell e DiMaggio (1983) chamaram de "pressões isomórficas", ou seja, pressões exercidas por meio de "preceitos" — regras institucionalizadas - entre as organizações de determinado campo, fazendo com que estas se moldem segundo um mesmo sentido (Moody, 2008), aquele de maior densidade — mais hegemônico.

As pressões fazem com que as organizações passem a compartilhar de "formas comuns" que caracterizam o campo organizacional existente, ou que possibilitam a construção de um novo campo organizacional. O fenômeno das pressões isomórficas foi estudado por Powell e DiMaggio (1983), que identificaram três mecanismos isomórficos: coerção, mimetismo e normatividade. O isomorfismo coercitivo diz respeito a pressões (formais ou informais) sofridas pelas organizações e exercidas por outras organizações do mesmo campo e por expectativas da sociedade; o isomorfismo mimético diz respeito a organizações que, não sabendo como agir em determinada situação ou para se adaptar a mudanças ainda incertas no campo, espelham-se naquelas organizações que já realizaram mudanças e parecem mais legitimadas ou bem-sucedidas; por fim, o isomorfismo normativo é fundamentado em processos de profissionalização, pelos quais as organizações alcançam patamar semelhante por meio de técnicas e normas comuns (Powell e Dimaggio, 1983). Nesse sentido, Bartley (2007) destaca que a disputa por financiamento é uma das principais pressões para a profissionalização de organi- 
zações, que ao se profissionalizarem passam a se diferenciar entre si, atendendo aos critérios de seleção dos financiadores.

Os três mecanismos, cada qual à sua maneira, constituem pressões que fazem com que organizações de um mesmo campo frequentemente apresentem características semelhantes, constituindo, portanto, processos isomórficos.

todos os tipos de mudanças organizacionais provocadas por processos isomórficos ocorrem como formas de facilitar o trabalho das organizações em diversas atividades: operações com outras organizações; recrutamento de profissionais; o reconhecimento como legítimo, organizações respeitáveis; e alinhamento que lhes permite participarem competições públicas e privadas. Estas atividades parecem, portanto, legitimar o campo organizacional. (Alves e Koga, 2006:70)

Detalhando um pouco mais as pressões sofridas em campos organizacionais, os autores (Alves e Koga, 2006) identificam que, no campo das organizações da sociedade civil, com a introdução da Lei no 9.790, de 1999, marco legal da criação das Oscips, as pressões isomórficas normativas e miméticas afetavam com mais frequência organizações mais "jovens", as mais antigas, em geral, não demonstraram adesão às pressões instauradas no campo organizacional, o que reflete inércia organizacional. O conceito de inércia organizacional, como esse caso demonstra, refere-se a organizações que, por estarem há muito tempo em determinado campo, já não sofrem os efeitos das pressões isomórficas e, portanto, não são "maleáveis", mantendo uma parte do campo substancialmente inalterada. Por outro lado, certas organizações que não se moldaram às pressões, devido à sua baixa legitimidade, acabam excluídas desse campo.

Além da dicotomia gerada pela inércia organizacional, há ainda um terceiro caso, no qual as organizações simultaneamente aceitam as mudanças, mas mantêm práticas anteriores. É o que os autores (Meyer e Rowan, 1977) chamam de decoupling, ou cerimonialismo, pelo qual as organizações criam mecanismos que simulam a adoção de novas práticas legitimadas pelo campo organizacional, por meio da "cerimônia", para lidar com as pressões, mantendo, entretanto, as práticas anteriores.

Em decorrência de processos isomórficos, as mesmas instituições que moldam um determinado campo, na medida em que permitem ideias e ações de determinadas organizações, podem restringir e limitar a atuação de outras, como mencionado por Moody, para quem "os repertórios construídos em um campo recentemente institucionalizado não só permitem ideias e ação, mas podem da mesma maneira restringi-los e limitá-los" (Moody, 2008:338, tradução nossa). Dessa forma, um campo organizacional é simultaneamente moldado e blindado pelas organizações que o constituem: organizações que não estão alinhadas ao isomorfismo do campo dificilmente conseguem adentrá-lo, enquanto aquelas mais densas são o padrão para a homogeneização.

A teoria institucionalista das organizações traz elementos que permitem analisar com mais precisão os efeitos gerados no caso proposto, o programa Cultura Viva. Isso porque o programa propõe incluir organizações até então excluídas da política pública de cultura. Ao 
serem incluídas, essas organizações passam a sofrer e exercer pressões, conforme será mais bem detalhado a seguir.

\section{0 programa Cultura Viva}

O programa Cultura Viva se diferencia de outros modelos de intervenção estatal para cultura adotados no Brasil nas últimas décadas, partindo de uma ideia simples: incentivar ações (culturais) que já existem no cotidiano de comunidades, para que, assim, essas ações ganhem força e consigam se perpetuar. Esse mecanismo, mesmo que simples, empodera comunidades e grupos culturais, já que estipula como será o incentivo - transferência de recursos por meio de convênios - , mas não delimita o tipo de manifestação cultural que será incentivada, desde que já seja realizada pelo grupo que se tornará ponto de cultura. São realizadas ações em linguagens tradicionais, como oficinas de dança e canto, ações não tradicionais, como a cibercultura e o grafite, e manifestações populares regionais, como o maracatu, o mamulengo e a contação de histórias. Segundo o MinC, o Cultura Viva tem por objetivo "implementar uma política cultural que atenda à diversidade e à abrangência que compõem a sociedade brasileira" (Minc, 2013).

As redes têm grande importância para o protagonismo e a autonomia das organizações e comunidades, uma vez que o programa é desenhado para incentivar o contato e a troca de saberes e experiências entre os pontos e pontões de cultura, como passam a ser chamadas as organizações culturais selecionadas por meio dos editais públicos (Minc, 2013). A fim de ampliar a atuação em rede, há ainda a modalidade de pontão de cultura, cujo objetivo é "articular os pontos de cultura de suas áreas de especialização, auxiliando na capacitação desses pontos de cultura e na difusão do conhecimento por eles produzido" (Minc, 2013). Por meio de contatos e parcerias, as organizações culturais buscam a ampliação de sua atuação e, em consequência, contribuem para a ampliação das redes de pontos e pontões de cultura. A noção de rede, além de crucial para a estruturação do programa, dá sentido para o próprio nome do programa: Cultura Viva, cultura que vive por meio das redes formadas pelo programa, que conectam os pontos, pontos estes de cultura (Turino, entrevista concedida em 22 de janeiro de 2013).

Com a implementação dos primeiros pontos de cultura em 2004, apenas cinco meses após a idealização do programa, o programa Cultura Viva se desenvolve rapidamente. Segundo Célio Turino, "o primeiro edital teve 800 inscrições, selecionamos 260 e foi possível conveniar 210. O segundo teve 2.500 inscrições, num prazo de 16 meses" (Turino, entrevista concedida em 22 de janeiro de 2013).

O início do programa Cultura Viva é então marcado pela aplicação dos conceitos norteadores que presidiram sua formulação - inclusão de novas manifestações culturais, de novos grupos atuantes nessa área e diversificação regional do acesso ao apoio governamental - e pela construção da rede de pontos de cultura, que tem um crescimento exponencial. O crescimento é favorecido pela criação, a partir de 2007, da "gestão compartilhada", no qual estados 
e municípios passam a dividir as responsabilidades financeiras e de gestão por meio de convênios firmados com o MinC, lançando editais para selecionar os chamados "pontos de rede". Dá-se início então às redes estaduais e municipais, ampliando significantemente o número de pontos e pontões de cultura ao redor do país.

\section{As alterações no campo organizacional da cultura}

Após aproximadamente oito anos de implantação do programa Cultura Viva, os números refletem crescimento dos convênios, enquanto pesquisas e avaliações realizadas apontam algumas limitações encontradas pelos pontos e pontões de cultura (Silva e Araújo, 2010; Medeiros, 2013), como baixa capacidade administrativa para gerenciar os convênios ou mesmo para orientar as organizações culturais.

Ao incluir organizações até então alheias à lógica governamental, geraram-se conflitos pelo fato de as organizações não estarem familiarizadas com práticas jurídicas necessárias para a correta execução de convênios. Por outro lado, a inclusão dessas organizações fez com que elas passassem a conhecer e trabalhar com novas lógicas, sobretudo a lógica burocrática, e deu visibilidade para outras formas possíveis de política cultural no Brasil, já que a política cultural passou a também incentivar ações culturais por formatos distintos do mecenato.

Esta seção aponta como a inclusão das organizações gerou pressões no campo organizacional da cultura, e busca esclarecer como tais pressões ocorreram e seus efeitos sobre o campo organizacional da cultura.

\subsection{Como a criação dos pontos de cultura afeta o campo organizacional da cultura}

O campo organizacional da cultura é um campo com organizações estabelecidas ao longo dos anos, sejam elas agências reguladoras, financiadoras, grandes produtoras e distribuidoras, bem como as organizações culturais, foco do presente artigo. Segundo pesquisa Fasfil, existiam oficialmente 290,7 mil Fundações Privadas e Associações sem Fins Lucrativos (Fasfil) no Brasil, correspondendo a 52,2\% do total de entidades sem fins lucrativos (556,8 mil) existentes (IBGE, 2010). Destas 209,7 mil entidades, 36,9 mil (12,7\%) são voltadas para Cultura e Recreação (IBGE, 2010). Conforme mencionado anteriormente, a escolha do estado de São Paulo se reforça pelo número de fundações privadas e associações sem fins lucrativos, aproximadamente 59,6 mil, ou seja, 20\% do total nacional. Destas, 7,6 mil (13\%) são voltadas para Cultura e Recreação (IBGE, 2010). A pesquisa Fasfil aponta ainda que a terceira principal atividade é cultura, em quantidade de entidades, sendo as entidades culturais localizadas em grande maioria $(77,4 \%)$ nas regiões Sudeste e Sul do país (IBGE, 2010).

A política pública de cultura estabelecida no país, sobretudo desde a década de 1990, dá grande destaque ao modelo de mecenato (Olivieri, 2004; Silva e Araújo, 2010), fazendo 
com que o campo organizacional da cultura paute-se fortemente no financiamento público de ações realizadas por organizações privadas (com ou sem fins lucrativos), por meio da renúncia fiscal. O financiamento público federal destinado à cultura se estrutura pelo Programa Nacional de Apoio à Cultura (Pronac), instituído pela Lei Rouanet, Lei no 8.313/1991 (MinC, 2013). O Pronac estabelece os recursos tanto destinados ao mecenato quanto ao Fundo Nacional de Cultura (FNC), que por sua vez financia programas de iniciativa do MinC, e pedidos individuais (MinC, 2013). Há ainda os Fundos de Investimento Cultural e Artístico (Ficart), que por apresentarem valores bastante inferiores não serão aqui analisados.

Os recursos do programa Cultura Viva são provenientes do FNC, uma fonte de recursos sem relação direta com o modelo de mecenato, e tratando-se de gestão compartilhada, há também recursos orçamentários dos estados e municípios. O orçamento do FNC cresce continuamente, para o programa Cultura Viva e também para os demais programas que se utilizam da mesma fonte de recursos.

Enquanto há disputa entre os programas financiados com recursos do FNC, os valores transferidos pelo mecenato, modelo de maior destaque na política cultural brasileira desde a década de 1990, têm crescimento no período.

Gráfico 1

Recursos transferidos pelo mecenato, por região - em milhares de reais

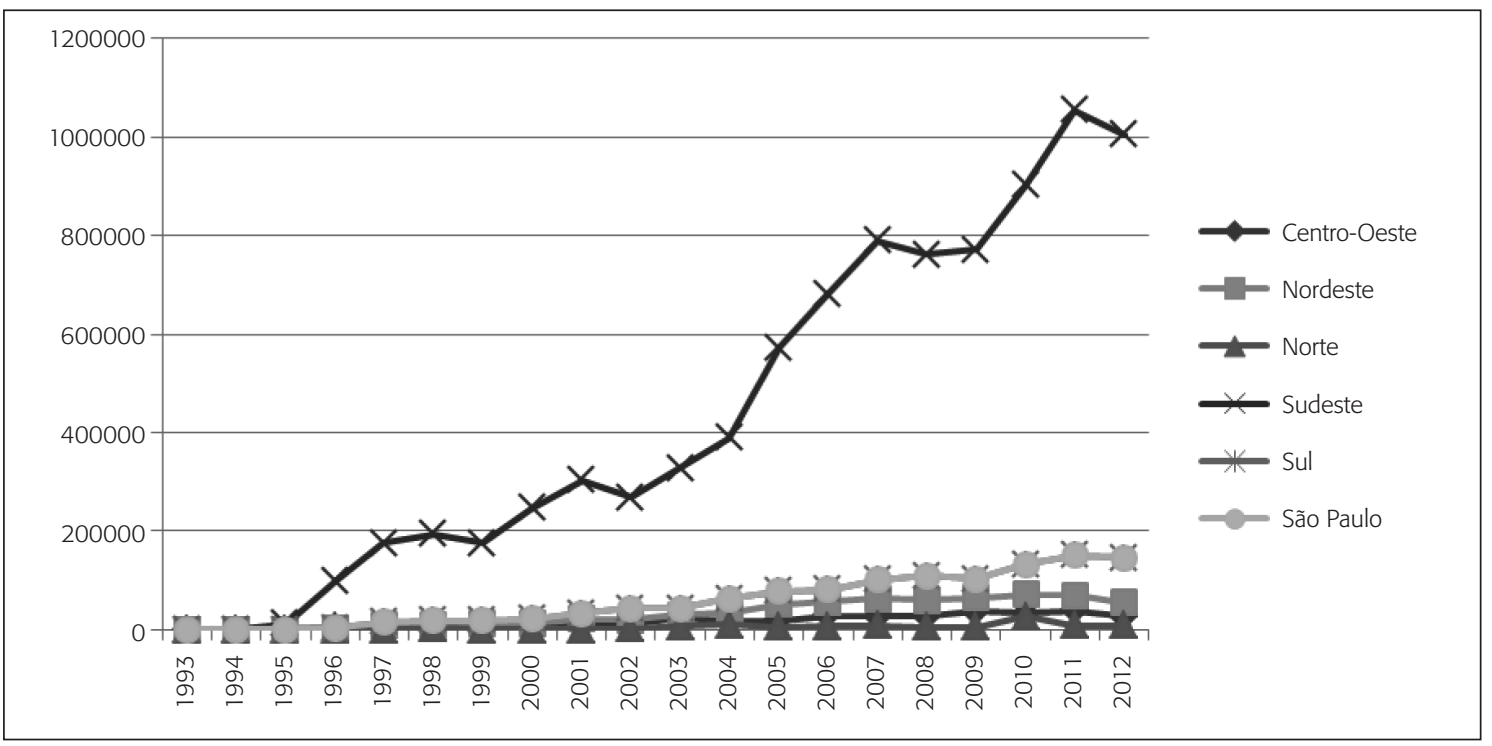

Fonte: Elaboração própria, com base nos dados de Salicnet (2013).

Há aumento de projetos financiados pelo mecenato, sobretudo a partir de 2004, data do início do programa Cultura Viva, uma vez que não há competição por recursos entre esses modelos. O campo organizacional da cultura é pouco afetado pela inclusão do programa Cul- 
tura Viva, dado que há crescimento de projetos, inclusive na região Nordeste, mesmo que de maneira mais modesta que o crescimento apresentado pela região Sudeste.

Além de apresentar concentração na região Sudeste, o volume de recursos transferidos pelo modelo de mecenato aponta como os investimentos nesse setor da política cultural tiveram crescimento após a implantação do programa Cultura Viva. Essa característica é importante para a presente análise pois, uma vez que os modelos de financiamento são financeiramente independentes, a inclusão do programa Cultura Viva, apesar de todos os seus méritos, não reflete disputa direta com o modelo de mecenato, dado que houve, tanto para o mecenato quanto para os demais programas financiados pelo FNC, ampliação de recursos, que acomodou distintas posições e não afetou as dinâmicas internas. Por outro lado, em termos simbólicos, são incluídas no campo organizações culturais com valores, histórico e tradições diferentes, e são essas as características, contra-hegemônicas, que permitem identificar conflitos gerados no campo organizacional pelo programa.

Reafirmando a importância de movimentos sociais para a continuidade ou mudança em campos organizacionais (Ruef, 2000), Barcellos (2012) destaca os movimentos sociais que buscaram propor mudanças no campo organizacional da cultura no mesmo período em que surge o programa Cultura Viva, ao dar legitimidade e visibilidade a organizações com linguagens e propostas distintas daquelas predominantes - e mais densas - no campo. Entre esses movimentos a autora (Barcellos, 2012) destaca o Circuito Fora do Eixo, que por sua vez conta com pontos de cultura em diferentes cidades do país.

Além do aspecto simbólico, uma importante mudança institucional no campo organizacional foi o Projeto de Lei no 757, de 2011. Escrito inicialmente pelas organizações culturais durante encontros periódicos dos envolvidos no Programa Cultura Viva (as Teias), e apresentado pela deputada Jandira Feghali (PCdoB/RJ), foi aprovado em 22 de julho de 2014, tornando-se a Lei no 13.018/2014, a qual institui a Política Nacional de Cultura Viva.

Entretanto, a proposta de mudança e inclusão não é plenamente assimilada pelo campo organizacional, dado que as organizações culturais que se tornam pontos de cultura, por serem distintas das organizações que compõem o campo, sofrem pressões institucionais e tendem a se assemelhar a essas organizações já componentes do campo. Com isso o campo se amplia e mantém as dinâmicas internas, e as organizações inseridas sofrem alterações, conforme será detalhado.

\subsection{Como os pontos de cultura são afetados por pressões institucionais}

Em princípio, os pontos e pontões de cultura reconhecem ações que já existem nas comunidades, mas devem seguir e se adequar às regras burocráticas, entendidas aqui como instrumentos externos de isomorfismo normativo. Ao submetê-los às regras burocráticas da máquina pública, surgem dificuldades e transformações no modo de atuação das organizações, característica apontada pelos dados do presente artigo, e também por outros pesquisadores, como Breschigliari (2010) e Barbosa e colaboradores (2011). 
Entre as dificuldades em lidar com regras burocráticas, destaca-se a exigência de seguir um plano de trabalho previamente proposto, independentemente das externalidades que possam vir a acontecer, ou a exigência de adoção de rígidos critérios de prestação de contas sem que houvesse qualquer contato anterior com esse tipo de procedimento por parte das organizações culturais (Medeiros, 2013).

Vale salientar que os gestores de pontos e pontões de cultura não questionam a necessidade de instrumentos de controle dos recursos e execução dos projetos. O que destacam é o fato de que a legislação vigente não condiz com a realidade dos movimentos culturais (Barbosa et al., 2011:70), sendo a mesma regra para todo e qualquer contrato que a administração pública direta e indireta venha a realizar. A desproporcionalidade desse nível de exigência para os projetos executados por pontos de cultura é exposta por seu idealizador:

A lógica de convênio é uma lógica ultrapassada. A legislação [Lei o 8.666/1993] é a mesma para fazer um contrato com uma grande obra de bilhões, como a transposição do rio São Francisco, e um contrato com um ponto de cultura numa pequena localidade no interior da Bahia que vai receber cinco mil reais com meia dúzia de mestres de terreiro. É a mesma lógica, e não tem cabimento. São objetos diferentes. (Turino, entrevista concedida em 22 de janeiro de 2013)

Gestores de pontos e pontões de cultura e diversos pesquisadores apontam as prestações de contas pendentes como o maior gargalo do programa Cultura Viva (Silva e Araújo, 2010; Medeiros, 2013; Silva et al., 2011). Muitas organizações culturais, sobretudo aquelas aprovadas nos primeiros editais do programa Cultura Viva, nunca tinham trabalhado com recursos públicos, e muitas ações foram realizadas sem a devida orientação, invalidando o uso dos recursos de acordo com o exigido pela Lei no 8.666/1993 (Medeiros, 2013). Em decorrência das prestações de contas pendentes, ou seja, por não se adequarem ao isomorfismo normativo, alguns pontos de cultura encontram-se com processos no Tribunal de Contas da União (TCU).

Ao serem inseridas no campo organizacional, as organizações passam a sofrer também pressões do campo em si, por meio da necessidade de adequar as organizações à linguagem burocrática. As exigências burocráticas atuam ainda no sentido de profissionalizar as organizações ao exigir cumprimento de normas técnicas, refletindo, portanto, isomorfismo normativo e coercitivo.

Por outro lado, organizações culturais familiarizadas com procedimentos burocráticos, ou seja, mais adaptadas a esses mecanismos institucionais coercitivos demonstram não sofrer impactos da baixa capacidade de gestão. São capazes de manter suas ações devido à sua estruturação preexistente, o que indica a densidade que elas possuem em relação ao campo organizacional (Ruef, 2000; Alves e Koga, 2006). Representantes dessas organizações, por sua vez, reconhecem nas entrevistas que organizações com menor estrutura não têm a mesma desenvoltura.

Nesse sentido, a burocracia se torna um gargalo para as organizações para manter um sistema vigente, e não necessariamente porque o modelo de pontos de cultura é inadequado: 
Quando você faz uma política pública focada na técnica você não muda as coisas e frequentemente retrocede. E isso o Cultura Viva que era um ponto mais de fronteira nesse pensar política pública. Mas o programa se burocratizou ainda mais. A alternativa do programa foi burocratizar, mortificar. Cultura Viva não é um nome aleatório, tem um sentido, que é a oposição entre vida e sistema, e isso se quebrou. A técnica sobrepõe ciclos e organizações voltam-se para a obtenção de recursos, mais do que o incentivo de ações (...) Não quer dizer que as ações deixem de ser feitas. As ações permanecem, mas perdem a dinâmica inicial e o incentivo para sua ampliação. (Turino, entrevista concedida em 22 de janeiro de 2013)

Pelos dados obtidos é possível afirmar que houve impacto nas organizações culturais, que, ao não se adequarem às regras burocráticas, passaram a sofrer diversas pressões isomórficas normativas e coercitivas. Em alguns casos, tais conflitos foram resolvidos por meio da "profissionalização" da organização e busca por outros financiadores, efeito que ocorreu em diversas outras organizações. A necessidade de se financiar por meio de outros projetos, bem como se profissionalizar para atender às exigências burocráticas, é entendida aqui como resultado de pressões isomórficas coercitivas. A partir do momento em que os pontos de cultura passam a competir entre si por recursos, a pressão coercitiva também ocorre no interior do programa Cultura Viva, dado que os pontos de cultura passam a exercer pressões entre seus pares.

Nove organizações não tinham nenhum projeto em vigor no momento de submissão do projeto de ponto de cultura. Após o reconhecimento como ponto de cultura, mais organizações passaram a contar com um, dois e três projetos simultâneos ao convênio que institui a organização como ponto de cultura.

Alguns gestores de pontos de cultura afirmam que os recursos não são suficientes para manter os pontos de cultura, referindo-se à necessidade que as organizações identificam de se profissionalizarem. A necessidade de profissionalização surgida em organizações recém-inseridas em um campo organizacional já foi identificada por outros autores, como no caso da análise da profissionalização das organizações sem fins lucrativos no Brasil quando da implementação do marco legal do Terceiro Setor (Alves e Koga, 2006). Esse processo reflete o que a teoria institucionalista aponta ao tratar da profissionalização como fator para emergência de um novo campo (Moody, 2008).

Nas palavras de um gestor, os recursos precisam ser ampliados "porque para contratar contador e funcionário é insuficiente" (Depoimento do Gestor 13, em resposta ao survey concedida em 17/10/2012). As organizações indicam que os recursos não são suficientes para garantir profissionais administrativos, como contadores, já que as funções administrativas são realizadas, em muitos pontos e pontões de cultura, por artistas. Com efeito, esses artistas passam a se preocupar mais com a estrutura administrativa do que com seu fazer cultural (Breschigliari, 2010; Silva et al., 2011; Medeiros, 2013).

Analisando as respostas concedidas pelas organizações que se tornam pontos de cultura, é possível aprofundar esse debate e destacar algumas percepções a partir das estruturas de gestão dos pontos de cultura, ou de sua ausência. A maioria das organizações (17 de 27 respostas) não contava com prestadores de serviço na data de sua fundação. Mesmo que timidamente e em 
contraposição ao argumento de que há poucos recursos, é possível perceber que as organizações ampliam o número de prestadores de serviço com o projeto de ponto de cultura, já que menos organizações não possuem algum prestador de serviços atualmente (10 de 23 respostas), além de mais organizações contarem com mais de cinco prestadores de serviços.

Por se tratar de pessoas jurídicas de direito privado sem fins lucrativos, as organizações contam com quadro de gestão, e a maioria das organizações possui um diretor e um coordenador, sendo o primeiro mais frequentemente à frente da organização, e o segundo mais frequentemente vinculado a projetos. A intenção de perguntar sobre os cargos de gestão foi identificar se há mais cargos fixos, ou seja, vinculados diretamente à organização, ou mais cargos vinculados a projetos. Pelos resultados obtidos, não é possível fazer tal inferência. Por outro lado, os gestores mencionaram cargos que não haviam sido considerados, inicialmente, e permitem ter ideia mais clara sobre a composição dos quadros de gestão das organizações.

As funções apontadas pelos gestores de pontos de cultura foram separadas em três ordens: (1) Ações Culturais, ou seja, funções voltadas a atividades finalísticas dos pontos de cultura; (2) Gestão, ou seja, funções intermediárias necessárias para garantir a execução das ações culturais; e (3) Governança, ou seja, aqueles cargos exigidos legalmente para a constituição de uma organização.

Apesar de não explicitar os efeitos da reorganização institucional em cada organização, no geral é possível destacar a importância dos atores intermediários, que exercem funções não necessariamente voltadas para a cultura, mas que permitem que esta seja realizada. É o caso do auxiliar administrativo, do tesoureiro, do secretário, entre outros cargos que tornam a organização mais profissionalizada, indicando que ocorre também no programa Cultura Viva isomorfismo normativo, decorrente da necessidade de que a organização trabalhe questões técnicas e administrativas. Tais atores intermediários são mais presentes em organizações de maior porte, dado que elas dispõem de mais projetos e recursos.

As organizações culturais que passam a ser pontos e pontões de cultura não estão alinhadas ao mainstream cultural, ou seja, não faziam parte do campo organizacional da cultura e, portanto, não tinham necessidade de se adequar à linguagem burocrática de financiamentos. Por não terem acesso a financiamento, não possuem vínculo com atores intermediários, como auxiliares administrativos e contadores habilitados para lidar com contratos públicos e convênios (Medeiros, 2013). Ao adentrarem o campo organizacional, passam a ter necessidade de entender e trabalhar com tais linguagens burocráticas.

Tais atores intermediários são em alguns casos incorporados pelas organizações por meio de contratos, em virtude do projeto de ponto de cultura. Por outro lado, grande parte das organizações não conta com recursos suficientes para contratar tais atores intermediários, e optam por contratar consultorias e empresas especializadas, pontualmente, sem criar vínculos permanentes. Já outras organizações, para suprir esse papel, passam a ter artistas que acumulam funções "burocráticas", que se especializam em linguagens com as quais não são familiarizados. Correm então o risco de perder o foco de sua ação cultural para garantir a gestão burocrática do convênio. Esse fator é apontado por alguns gestores de pontos de cultura como crítico: 
Antes do edital nós nunca tivemos a oportunidade de gerir verbas públicas. Isso nos amadureceu, permitiu ter uma sede capaz de realizar eventos culturais diversos, receber grupos de teatro. Também administramos seis editais públicos para projetos culturais. Passamos a ser atores culturais importantes e empoderados. [Mesmo empoderados] percebemos que o recurso nos transformava em produtores culturais e não havia uma renda para pagar nossos serviços. Passamos a existir, mas continuamos explorando nosso trabalho sem que alterasse nossa qualidade de vida. Ganhamos respeito, posição política, novos parceiros, evidência e experiência. No entanto, não conseguimos ganhar autonomia econômica. Concorremos novamente ao mesmo edital e ao mesmo valor, mas sabendo que de algum modo exploramos nosso trabalho para executar um projeto cultural que o Estado gastaria o dobro ou triplo para se aproximar do que realizamos. (Depoimento do Gestor 21, em resposta ao survey concedida em 1 de dezembro de 2012)

Vale salientar ainda que, em alguns casos, os gestores afirmam não contar com estruturas de gestão. Isso porque muitas organizações (sete) relataram não ter funcionários, e trabalham com voluntários e prestadores de serviços autônomos. Mesmo sendo uma característica da ação cultural comunitária, vale a reflexão sobre não remunerar tais pessoas, o que pode tanto valorizar seu fazer cultural quanto demonstrar a precarização do trabalho nos pontos de cultura, dado que os recursos não são suficientes para a ajuda necessária.

Com a profissionalização das organizações culturais, é possível afirmar que tais organizações passam a se solidificar no campo organizacional da cultura. É possível perceber como algumas organizações, diante das dificuldades de terem seu primeiro contato com o financiamento público, passam a se estruturar para poder lidar com os recursos de forma mais "profissional". Passado o primeiro contato com o financiamento público, houve aprendizagem, reforçando a característica mimética do programa, fortemente identificada pela forma como os pontos de cultura afetam a si próprios.

\subsection{Como os pontos de cultura afetam a si próprios}

Como aponta Barbosa e colaboradores (2011), a heterogeneidade das organizações que se tornam pontos de cultura deve ser constantemente ressaltada para evitar generalizações, mas há um cerne em comum: o desenho do programa Cultura Viva é estruturado pela atuação em rede, que faz com que os pontos de cultura influenciem uns aos outros, e inclusive organizações não conveniadas, como descrevem gestores de pontos de cultura, para quem "a rede inclui todo mundo, que já foi, que quer ser. A rede é [composta de] todos os convênios juntos, mais quem não tem convênio" (Depoimento do Gestor 4, em entrevista concedida em 24 de janeiro de 2013).

A atuação em rede permite que os pontos de cultura troquem conhecimentos e experiências: os gestores aprendem com "exemplos a serem seguidos" e se unem para realizar novas ações. São frequentes relatos de pontos de cultura que se articulam e se complementam para realizar novas ações, como é possível observar pelo relato: 
[A rede acontece] quando um ponto vai para o outro, e essa interação é muito grande. Pelo menos com a gente acontece sempre. Por exemplo, a gente fez um fanzine (uma revista ilustrada, com desenhos, notícias e outras informações) com outros pontos. Teve um pessoal de outro clube que compartilhou seu acervo, e fizemos oficinas, houve debate. O ponto de cultura A também já compartilhou acervo, teve oficineiro que se formou com eles e deu oficina na nossa cidade. Também fizemos muita coisa com o ponto de cultura B, além de outros. (Depoimento do Gestor 4, em entrevista concedida em 24 de janeiro de 2013)

As relações estabelecidas entre os pontos de cultura tornam-se estratégicas para o desenvolvimento e o fortalecimento de suas ações, e uma vez que podem atuar colaborativamente, os pontos de cultura passam a se empoderar, pois somam suas potencialidades e saberes, sendo legitimados pelo reconhecimento de uma política pública federal, e por ela financiados. A importância das redes formadas é evidenciada pela literatura institucionalista, dado que para Moody (2008) as redes garantem crescimento e manutenção do campo, e a busca de "exemplos a serem seguidos" e conhecimentos repassados para melhorar as práticas das organizações, o que solidifica a percepção de modelos mais legítimos, criando uma nova pressão institucional de natureza mimética. Tais características são verificadas no programa Cultura Viva, como é possível perceber pelo depoimento:

A rede de Pontos de Cultura expandiu nossos conhecimentos em relação à Cultura e aos povos brasileiros, e também ampliou nossos contatos com os demais fazedores culturais. Ter contato com gente da gente, gente que faz Cultura, que faz da Cultura a forma de vida, é extraordinário. (Depoimento do Gestor 10, em resposta ao survey concedida em 27 de setembro de 2012)

Vale pontuar que há casos de pontos de cultura alheios às redes existentes. Silva e colaboradores (2011) apontam que há instituições que não se identificam como pontos de cultura, fragilizando a rede formada, não sendo, porém, a maioria. Para os autores (Silva et al., 2011), há diferentes graus de atuação e articulação, desde pontos de cultura mobilizadores, até pontos de cultura limitados à sua linguagem cultural e comunidade.

Para a maioria dos gestores que responderam ao survey e para todos os gestores entrevistados, interações entre agentes culturais não eram realizadas antes do incentivo trazido pelo programa Cultura Viva. Pesquisa realizada com gestores de pontos de cultura (Silva et al., 2011) aponta ainda que alguns pontos de cultura fortaleceram sua articulação comunitária, aumentando inclusive a visibilidade pública das ações culturais, já que incentivam parcerias entre os pontos de cultura, entre outros colaboradores e entre os diferentes níveis de governo (Silva et al., 2011).

Grande enfoque é dado pelo programa para as redes presenciais, ou seja, encontros como as teias, e vínculos entre pontos de cultura que realizam ações em conjunto, já que esses encontros favorecem a disseminação de trocas e o fortalecimento de práticas culturais, bem como dinamizam circuitos e a própria rede de pontos de cultura (Silva et al., 2011). 
Outra manifestação dessa rede, tida entre gestores de pontos de cultura como importante, é a comunicação gerada, representada pela rede virtual, ou seja, grupos de discussão e mobilização que trocam mensagens e divulgação de ações por meio da internet. Por outro lado, há estudos que apontam que a inexistência de sistematização das informações sobre conclusão de projetos selecionados pelos primeiros editais e inclusão dos projetos posteriores pode prejudicar a construção do conhecimento e da memória acumulados com a interação entre os pontos de cultura (Silva e Araújo, 2010; Silva et al., 2011).

\section{Considerações finais}

Este artigo teve por objetivo analisar transformações ocorridas no campo organizacional da cultura no estado de São Paulo a partir da implementação do programa Cultura Viva, ou seja, como efeito de uma política pública, utilizando elementos da teoria institucionalista das organizações para analisar com mais precisão os efeitos gerados no caso proposto. O caso permite afirmar algumas hipóteses e confirmar características apontadas pela teoria institucional: (1) o campo organizacional da cultura brasileiro é fortemente marcado pelo padrão, ou forma, do modelo de mecenato, que estipula quais organizações possuem maior densidade, pois (2) aquelas organizações e instituições mais fortes - e mais densas - permanecem como principais atores do campo organizacional, independentemente das propostas de mudança em curso, dado que (3) organizações que já possuem densidade - no caso, por serem estruturadas como organizações antes da criação do programa Cultura Viva — não sofrem impacto das pressões isomórficas e perpetuam a inércia organizacional.

Por outro lado, as organizações não legitimadas no campo organizacional apresentam diferentes características. Muitas organizações, (4) para se adequarem ao campo, se profissionalizam e tornam-se aptas a disputar as linhas de financiamento existentes, ao atenderem aos critérios de seleção dos financiadores; (5) outras organizações não se adequam ao campo organizacional da cultura por sofrerem as pressões isomórficas exercidas em tal campo; e há ainda (6) algumas organizações que optam por não se adequarem ao campo, resistindo às pressões isomórficas como forma de busca por uma mudança ainda maior.

Destaca-se que a inserção das organizações não gerou impacto financeiro no campo organizacional, o que permitiu a manutenção do programa Cultura Viva concomitantemente às demais estruturas do campo organizacional da cultura. Dessa forma, (7) o caso aponta como houve assimilação, e não ruptura, tal qual proposto inicialmente. Verificou-se que a inclusão de novas organizações culturais, mais do que mudar o padrão existente no campo organizacional da cultura, fez com que essas organizações apenas se adequassem a esse campo. Utilizando uma visão dicotômica entre os modelos do mecenato e do programa Cultura Viva, há, no lugar de ruptura com um modelo anterior, reprodução da lógica interna ao campo organizacional da cultura. 


\section{Referências}

ALVES, Mario A.; KOGA, Natália. Brazilian nonprofit organizations and the new legal framework: an institutional perspective. Brazilian Administration Review - BAR, v. 3, n. 2, p. 68-83, jul./dez. 2006.

BARBOSA, Cláudia L.; MEDEIROS, Rosana C. F.; LYRA, Valéria M. G. Avaliação dos Pontões de Cultura do Programa Cultura Viva. O olhar dos gestores do Programa Cultura Viva. Relatório da Pesquisa Avaliativa do Programa Cultura Viva. Brasília: Ipea, 2011.

BARCELLOS, Rebeca. Por outro eixo, outro organizar: a organização da resistência do circuito fora do eixo no contexto cultural brasileiro. Tese (doutorado) - Centro Socioeconômico, Programa de Pós-Graduação em Administração, Universidade Federal de Santa Catarina, Florianópolis, 2012.

BARLEY, Stephen R.; TOLBERT, Pamela S. Institutionalization and structuration: studying the links between action and institution. Organization Studies, v. 18, n. 1, p. 93-117, 1997.

BARLEY, Steve. Building an institutional field to corral a government: a case to set an agenda for organization studies. Organization Studies, v. 31, n. 6, p. 777-805, jun. 2010.

BARTLEY, Tim. How Foundations shape social movements: the construction of an organizational field and the rise of forest certification. Social Problems, v. 54, n. 3, p. 229-255, ago. 2007.

BRESCHIGLIARI, Juliana. Transformação e transmissão da cultura popular: diálogos com as políticas públicas de patrimonialização. Cadernos Gestão Pública e Cidadania, v. 15, n. 57, p. 234-253, 2010.

BOURDIEU, Pierre. Razões práticas: sobre a teoria da ação. Campinas: Papirus, 1996.

EMIRBAYER, Mustafa; MISCHE, Ann. What is agency? American Journal of Sociology, v. 103, n. 4, p. 962-1023, 1998.

FLIGSTEIN, Neil; MCADAM, Doug. A theory of fields. Nova York: Oxford University Press, 2012. (Edição Kindle, referenciado nas posições 4392-403).

HALL, Peter A.; TAYLOR, Rosemary C. R. As três versões do neoinstitucionalismo. Lua Nova, n. 58, p. 193-223, 2003.

IBGE. Instituto Brasileiro de Geografia e Estatística. Fasfil, As Fundações Privadas e Associações sem Fins Lucrativos no Brasil. Estudos e Pesquisas, Abong, Ipea e Gife. Rio de Janeiro: IBGE, 2010.

KENIS, Patrick; KNOKE, David. How organizational field networks shape interorganizational tie-formation rates. The Academy of Management Review, v. 27, n. 2, p. 275-293, abr. 2002.

MARQUES, Eduardo C. Notas críticas à literatura sobre Estado, políticas estatais e atores políticos. BIB: Boletim Bibliográfico de Ciências Sociais, v. 43, p. 67-102, 1997.

MEDEIROS, Anny K. Políticas públicas e organizações culturais: o caso do programa Cultura Viva. Dissertação (mestrado) — Escola de Administração de Empresas de São Paulo, Fundação Getulio Vargas, São Paulo, 2013. 
MEYER, John W.; ROWAN, Brian. Institutionalized organizations: formal structure as myth and ceremony. American Journal of Sociology, v. 83, p. 340-363, 1977.

MILWARD, H. Brinton. Interorganizational policy systems and research on public organizations. Administration \& Society, v. 13, n. 4, p. 457-478, 1982.

MINC. Ministério da Cultura. Programa Arte Cultura e Cidadania - Cultura Viva. Disponível em: <www.cultura.gov.br/culturaviva/cultura-viva/>. Acesso em: 16 nov. 2013.

MOODY, Michael. Building a culture: the construction and evolution of venture philanthropy as a new organizational field. Nonprofit and Voluntary Sector Quarterly, v. 37, n. 2, p. 324-352, 2008.

OLIVIERI, Cristiane G. Cultura neoliberal: leis de incentivo como políticas públicas de cultura. São Paulo: Escrituras, 2004. (Visões da Cultura).

PETER, Guy; PIERRE, Jon; KING, Desmond S. The politics of path dependency: political conflict in historical institutionalism. The Journal of Politics. v. 67, n. 4, p. 1275-1300, 2005.

PIERSON, Paul. Increasing returns, path dependence, and the study of politics. American Political Science Review, v. 94, n. 2, p. 251-267, 2000.

PIERSON, Paul. Politics in time: history, institutions, and social analysis. Nova Jérsei: Princeton University Press, 2004.

PORTAL DA TRANSPARÊNCIA. Governo Federal. Disponível em: <www3.transparencia.gov.br/> . Acesso em: 16 de nov. 2013.

POWELL, Walter; DIMAGGIO, Paul. The iron cage revisited: institutional isomorphism and collective rationality in organizational fields. In: POWELL, Walter; DIMAGGIO, Paul (Org.). The new institutionalism in organizational analysis. Chicago: Chicago University Press, 1983. p. 63-81.

RAO, Hayagreeva; MORRILL, Calvin; ZALD, Mayer N. Power plays: how social movements and collective action create new organizational forms. In: STAW, Barry M.; SUTTON, Robert I. Research in organizational behavior. Nova York: Elsevier; JAI, 2000. p. 237-282.

REAY, Trish; HININGS, Christopher Bob. The recomposition of an organizational field: Health care in Alberta. Organization Studies, v. 26, n. 3, p. 351-384, 2005.

REIS, Ana C. F. Marketing cultural e financiamento da cultura: teoria e prática em um estudo internacional comparado. São Paulo: Pioneira Thomson Learning, 2003.

RODARTE, Bárbara. Coordenadora do programa Cultura Viva na Secretaria de Estado da Cultura de São Paulo. Entrevista concedida em 22/3/2010 na Secretaria de Estado da Cultura de São Paulo (São Paulo), 2010.

RUEF, Martin. The emergence of organizational forms: a community ecology approach. American Journal of Sociology, v. 106, n. 3, p. 658-714, 2000.

SALICNET. Portal SalicNet para base de dados do Programa Nacional de Apoio à Cultura - Pronac. Disponível em: <http://sistemas.cultura.gov.br/salicnet/Salicnet/Salicnet.php\#>. Acesso em: 16 nov. 2013. 
SEO, Myeong-Gu; CREED, We Douglas. Institutional contradictions, praxis, and institutional change: a dialectical perspective. Academy of Management Review, v. 27, n. 2, p. 222-247, 2002.

SIC. Sistema de Informação da Cultura. Lei de Acesso à Informação. Brasília: MinC, 2012.

SILVA, Frederico A. Barbosa da; ARAÚJO, Herton Ellery. Cultura viva: avaliação do Programa Arte Educação e Cidadania. Brasília: Ipea, 2010.

SILVA, Frederico A. Barbosa da et al. Cultura viva: as práticas de pontos e pontões. Brasília: Ipea, 2011.

THELEN, Kathleen. Historical institutionalism in comparative politics. Annual Review of Political Science, v. 2, p. 369-404, 1999.

TURINO, Célio. Formulador do programa Cultura Viva e secretário de Cidadania Cultural do Ministério da Cultura entre 2004 e 2010. Entrevista concedida em 22/1/2013 em São Paulo, 2013.

Anny Karine de Medeiros é mestre em administração pública e governo pela Escola de Administração de Empresas de São Paulo da Fundação Getulio Vargas (FGV-Eaesp). E-mail: annykmedeiros@gmail.com.

Mário Aquino Alves é doutor em administração pela Escola de Administração de Empresas de São Paulo da Fundação Getulio Vargas (FGV-Eaesp) e professor adjunto da FGV-Eaesp. E-mail: mario.alves@fgv.br.

Marta Ferreira Santos Farah é doutora em sociologia pela Faculdade de Filosofia, Letras e Ciências Humanas da Universidade de São Paulo (FFLCH-USP) e professora titular da Escola de Administração de Empresas de São Paulo da Fundação Getulio Vargas (FGV-Eaesp). E-mail: marta.farah@fgv.br. 